\title{
COGNITIVE IMPAIRMENT AND DEPRESSION ARE THE MOST IMPORTANT RISK FACTORS FOR FRAILTY
}

\author{
Tita Hariyanti ${ }^{1}$, Sri Sunarti ${ }^{1}$, Seravina Ayu Vistiandini ${ }^{1}$ \\ Correspondence: tita.hariyanti@gmail.com \\ ${ }^{1}$ Department of Public Health Faculty of Medicine Brawijaya University, Malang, Indonesia.
}

Article History:

Received: February 22, 2018

Accepted: November 25, 2019

Published: January 1, 2020

\section{Cite this as:}

Hariyanti T, Sunarti S, Seravina VA.

Geriatric Constipation. Malang

Neurology Journal; 2020.6: 20-23.

http://dx.doi.org/10.21776/ub.mnj.202 0.006 .01 .4

\section{ABSTRACT}

Background: Frailty is a condition that causes a decline or failure in homeostasis mechanism on older people resulting in increased susceptibility to stressor. The risk factors of frailty include: cognitive impairment and depression.

Objective: To prove the relation between cognitive impairment and depression with frailty.

Methods: This study is using cross sectional approach. Samples are collected from 222 citizens from the elderly population of Malang using accidental sampling method. Variables measured in this study are frailty that is determined by Fried Criteria, cognitive impairment that is determined by MMSE score and depression status that is determined by GDS score.

Results: The analysis result of relation between cognitive impairment and depression and frailty using the Spearman correlation test produces the value of $p=0,000$ and the correlation coefficients for rare 0,500 and 0,508 respectively. Different levels of cognitive impairment and depression in the frail group compared to pre-frail and robust groups resulted in $\mathrm{p}=0,000$, whereas the level of cognitive impairment and depression in the pre-frail group compared to robust group yielding p values of 0.735 and 0.944 respectively.

Conclusion: There is a relation between cognitive impairment and depression on frailty. There was a significant difference in the levels of cognitive impairment and depression in the frail group compared to the pre-frail and robust groups, whereas in the pre-frail group compared to robust group the levels of cognitive impairment and depression did not have a significant difference.

Keywords: Cognitive impairment, Depression, frailty, pre-frail, robust

\section{Introduction}

Based on research conducted in the United Kingdom (UK) using the Fried Criteria (Cardiovascular Health Study), it shows that the most prevalent frailty is in the age of $64-74$ years with a ratio of $1: 2$ between men and women. The prevalence continues to increase in accordance with increasing age. The percentage of frailty incidence is $10-25 \%$ at the age of $\geq 65$ years old. Of these, $30-45 \%$ of the elderly are $\geq 85$ years old. ${ }^{1}$

Frailty is a condition that can cause a decrease or failure of the homeostasis mechanism in the elderly which results in increased vulnerability to stressors. These stressors can be intrinsic, such as infection or extrinsics, such as changes in the environment. Such condition will result in increased risk of harmful situation such as falls, delirium and disability. Elderly people who experience frailty will experience a decrease in functional status even though they only experience minor illnesses, and the recovery of minor illnesses cannot restore their functional status as in the initial state. ${ }^{1,2}$ Frailty can cause various consequences such as increased incidence of falls, dependence, hospitalization, institutionalization, morbidity and even mortality. ${ }^{3}$ The frailty diagnosis can be determined based on Fried Criteria which consists of a combination of five components, namely weight loss, self-reported exhaustion, weakness, slowness and reduce physical activity. If the elderly do not fulfill the five components above, they are said to be robust or no frail. If they meet 1 or 2 components, it is called pre-frail and if they meet 3 or more components, it is called frail.

The most frequent impacts arising from frailty are falls, delirium, fluctuating disability and various non-specific symptoms such as excessive fatigue, increased infection and weight loss without known cause. ${ }^{5}$ There are several things that can increase the risk of frailty. These risk factors include cognitive impairment and depression. Older people who have cognitive impairment have a greater risk of experiencing frailty compared to the elderly who do not have cognitive impairments. ${ }^{6}$ Cognitive impairment in the elderly can be caused by a process called brain aging. ${ }^{7}$ Cognitive impairment will cause a loss of ability to interpret speech or writing, so it can make the elderly not be able to live independently. ${ }^{8}$ In addition to cognitive impairment, depression can also increase the prevalence and incidence of frailty. The incidence of frailty will be greater in the elderly who are depressed compared to the elderly without depression. This happens because depression can cause the elderly to experience a decline in social function and physical activity so that they will fall into frail condition.

The general objective of this study is to analyze the relationship between cognitive impairment and depression on frailty condition in the elderly in Malang City. In addition, different tests will be carried out at the level of cognitive impairment and depression in each frailty group. The status of cognitive impairment will be determined based on the MMSE 
score, whereas depression status will be determined using the GDS score.

\section{Methods}

The study design was analytical observational. Data was taken by cross sectional method because the data was collected through interview regarding the risk factors for cognitive impairment and depression and physical examination related to the incidence of frailty in the citizen of Malang City at one time. The results obtained are then analyzed statistically to obtain correlations between variables. The sample in this study was taken from the population of Malang City, East Java. The criteria for the samples taken were citizens age $\geq 60$ years old and were willing to be the subject of the study which were proven by signing the form of willingness to be respondent.

This study uses accidental sampling method. Sampling was done at Karang Werda meeting, integrated health service post (posyandu) and elderly gymnastics in five sub-districts of Malang City. Data collection was carried out in May 2017. The sample size was determined based on the infinite population formula so that the sample quota of 279 people was obtained.10 However, after the research was carried out, the quota target was not fulfilled and the sample collected was only 222 people. The distribution of respondents can be seen from the following table.

Table 1. Distribution of respondents

\begin{tabular}{llc}
\hline No & Sub-dictricts & Number of Samples \\
\hline 1 & Klojen & 22 \\
2 & Lowokwaru & 48 \\
3 & Sukun & 71 \\
4 & Blimbing & 57 \\
5 & Kedungkandang & 24 \\
\hline & Total & $\mathbf{2 2 2}$
\end{tabular}

Source: research results, 2017

The dependent variable in this study is the frailty condition which consists of three categories, namely robust, pre-frail and frail. The control variable is Malang City residents who are more than or equal to 60 years old. Frailty diagnosis was determined through Fried Criteria consisting of a combination of five components (weight loss, self-reported exhaustion, reducing physical activity, slowness and weakness). ${ }^{4}$ The independent variables in this study were cognitive impairment and depression.

Cognitive impairment is determined through Mini Mental State Examination (MMSE) score. MMSE consists of 11 questions that will examine the five cognitive functions, namely: orientation, registration, attention and calculation, repetition of words that are spoken (recall) and language. The maximum score is 30 . If the score is 24 or less, it indicates cognitive impairment. The time needed to carry out MMSE is 5-10 minutes. ${ }^{12}$ Meanwhile, to determine depression status, the Geriatric Depression Scale (GDS) Short Form consisting of 15 questions is used. This interview can be completed in 57 minutes. If the elderly get a score of $\leq 5$, it is declared negative depression. If they get a score of $6-9$, it is probable that they experience depression. If they get a score of $10-15$, it is declared positive depression. ${ }^{11}$

The tool used in this study is a meter to measure height, a stopwatch to measure the speed of walking and a hand held dynamometer to measure grip strength. The research instruments used were MMSE survey sheets, GDS and Fried Criteria.

The research data are in the form of cognitive status grouped in definite and negative categories, depression status grouped in positive, negative and probable categories and frailty status is grouped into robust, pre-frail and frail. If the 5 components are not met, it is called robust. If 1 or 2 components are met, it is called pre-frail. If $\geq 3$ components are met, it is called frail. The data are classified as ordinal so that the analysis method used is non parametric test. Relationship analysis was carried out using the Spearman correlation test. The analysis on the level of difference was done by using Mann-Whitney $U$ test. The data were analyzed and processed with SPPS v. 21 with $\mathrm{p}$ values of 0.05 and Confident Interval $(\mathrm{CI}=95 \%)$.

\section{Results}

From the results of the study, an overview of the characteristics of the respondents was obtained. The characteristics of respondents in this study can be seen in the table as follows:

Table 2. Respondent characteristics

\begin{tabular}{|c|c|c|}
\hline Characteristics & Number (n) & $\%$ \\
\hline Number of subject & 222 & 100 \\
\hline \multicolumn{3}{|l|}{ Age } \\
\hline $60-64.9$ years & 69 & 31 \\
\hline $65-69.9$ years & 53 & 24 \\
\hline $70-74.9$ years & 49 & 22 \\
\hline$\geq 75$ years & 52 & 23 \\
\hline \multicolumn{3}{|l|}{ Sex } \\
\hline Male & 47 & 21 \\
\hline Female & 175 & 79 \\
\hline \multicolumn{3}{|l|}{ Frailty Status } \\
\hline Frail & 79 & 36 \\
\hline Pre-frail & 103 & 46 \\
\hline Robust & 40 & 18 \\
\hline \multicolumn{3}{|l|}{ Cognitive Status } \\
\hline Definite & 97 & 44 \\
\hline Normal & 125 & 56 \\
\hline \multicolumn{3}{|l|}{ Depression Status } \\
\hline Positive & 58 & 2 \\
\hline Negative & 151 & 68 \\
\hline Probable & 13 & 6 \\
\hline
\end{tabular}

The relationship between cognitive impairment and frailty was also analyzed using Spearman's correlation. From the analysis, the significance value of $p<0.000$ was obtained. The coefficient of correlation $r$ was 0.5000 . This indicates a moderate relationship between the level of cognitive impairment and frailty. From the results of the analysis of the relationship between depression and frailty using the Spearman correlation test, a significance value of $\mathrm{p}<0.000$ and correlation coefficient $r$ of -0.508 were obtained. From these results it can be concluded that there is a significant relationship between depression and frailty.

Based on the results of the analysis of the different level of cognitive impairment in the frail group compared to the level of cognitive impairment in pre-frail and robust groups using Mann-Whitney $U$ difference test, $p=0.000$ is obtained. This means that there is a significant difference between the level of cognitive impairment in the frail group compared to that of pre-frail and robust groups. From the results of analysis of the 
differences in the level of cognitive impairment in the pre-frail group compared to that in the robust group using the same test, $p$ value $=0.735$ is obtained. It means that the level of cognitive impairment does not have a significant difference in the two groups. The results of the above analysis are shown in the following figure:

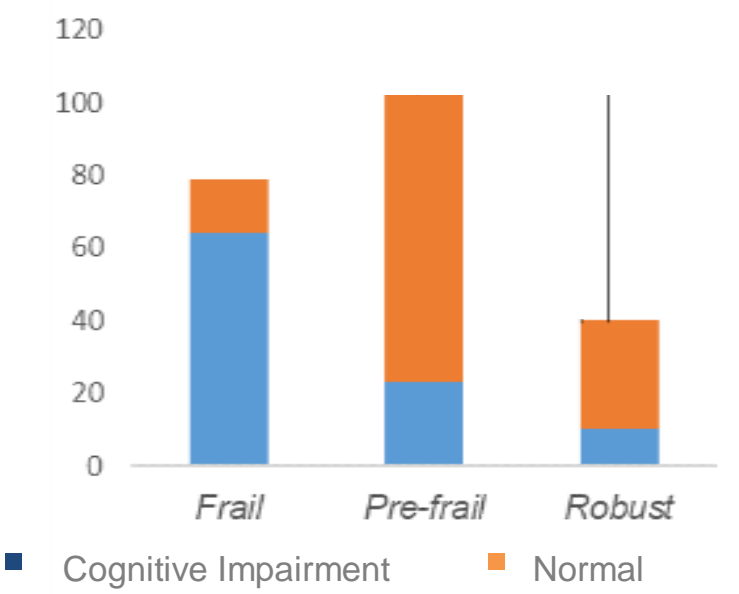

Figure 1. Differences in cognitive impairment in the frailty group

Based on the results of the analysis of different levels of depression in the frail group compared to the levels of depression in pre-frail and robust groups using the MannWhitney $U$ difference test, $p=0.000$ was obtained. This means that there is a significant difference between the level of depression in the frail group compared to that in pre-frail and robust groups.

Based on the results of analysis of the difference in depression levels in pre-frail group compared to depression levels in robust group using the same test, it is known that $\mathrm{p}$ value = 0.944 . Based on this result it can be concluded that there is no significant difference between the levels of depression in the two pre-frail groups compared to those in robust group. The results of the above analysis are shown in the following figure:

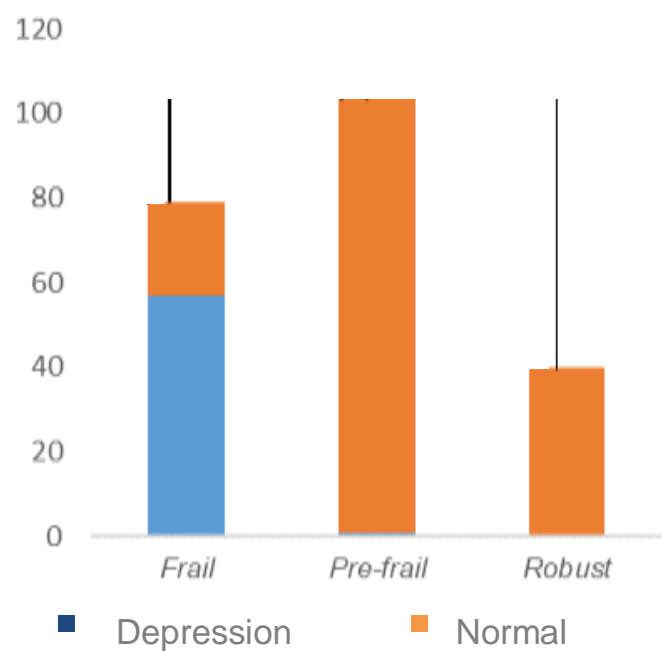

Figure 2. Differences in depression status in the frailty group

Figure 2 shows that there is significant difference between the level of depression in the frail group compared to that in prefrail and robust groups.

\section{Discussion}

After the analysis, the results of this study showed that there was a significant relationship between depression and frailty. This result is in line with previous studies which state that depression and frailty have a strong relationship. ${ }^{15}$

The relationship between depression and frailty can form a cycle. Depression experienced by the elderly can cause a decrease in muscle strength and physical activity which will lead to functional limitation in the elderly and cause frailty. ${ }^{16}$ Depression can also cause a decrease in the regulation of the system of neurotransmitters in the brain such as dopamine and norepinephrine. A decrease in these neurotransmitters can result in decreasing motivation to do physical activity. Such conditions will increase the risk of frailty. 8 In addition, depression in the elderly can be a predictive factor of frailty due to a decrease in social function, an increased risk of falls, weight loss and malnutrition. ${ }^{9}$

This study also examines the differences in the level of cognitive impairment in the frail group compared to that in pre-frail and robust groups. Based on the results of the analysis it was found that the level of cognitive impairment in those groups had a significant difference. These results are in line with previous studies which showed that the prevalence of cognitive impairment was higher in the frail population compared to that in other populations, therefore, the high degree of frailty could show predictions of cognitive impairment. ${ }^{8}$ The levels of cognitive impairment in pre-frail and in robust groups did not have a significant difference. These results are in accordance with previous studies which also stated that there was no significant difference between the level of cognitive impairment in the pre-frail group compared to that in the robust group. ${ }^{18}$

The mechanism of high rates of cognitive impairment in the frail population can be caused by the presence of cardiovascular disease. A decrease in muscle strength in the frail condition will cause a decrease in walking ability. This will result in a decrease in physical activity, and thus will increase the risk of cardiovascular disease which can contribute to the occurrence of cognitive impairment. For example, heart failure can reduce blood flow to the brain, so the supply of oxygen and nutrients to the brain becomes inadequate and can result in the death of brain cells in various places, including the cortex area which is associated with learning, memory and language. ${ }^{18}$ In this study it was found that there was a significant difference between the level of depression in the frail group compared to that in pre-frail and robust groups. This is in line with previous research which stated that the level of depression was higher in the frail group compared to that in pre-frail and robust groups. ${ }^{19}$ The levels of depression in pre-frail and in robust groups did not have a significant difference. This result is also in accordance with previous studies which showed that there was no significant difference in the levels of depression between the pre-frail and robust group. ${ }^{20}$ The mechanism of high levels of depression in the frail population can be caused by disability or functional limitation caused by various factors such as impaired balance, muscle strength, impaired weakness mobility, low endurance, etc. Apart from these reasons, frail can also cause symptoms of depression due to a decrease in functional abilities and social withdrawal. $^{21}$ 


\section{Conclusion}

Based on the results of research on the relationship between cognitive impairment and depression on frailty in 222 subjects in Malang City, it can be concluded that there is a relationship between cognitive impairment and frail condition. More subjects with cognitive impairment are found in the frail group rather than in the pre-frail and robust groups. There is also a relationship between depression and frail condition. More subjects who experience depression are found in the frail group rather than in the pre-frail and robust groups.

\section{References}

1. Halter JB, Ouslander JG, Tinetti ME, Studenski S, High KP, Asthana S. Hazzard's Geriatric Medicine and Gerontology. Ed 6., McGraw-Hill Publishing. United States; 2009. ISBN 978-0-07-148872-3

2. Clegg A, Young J. The Frailty Syndrome. Clinical Medicine; 2011.11(1):72-5. DOI: $10.7861 /$ clinmedicine.11-1-72.

3. Rebecca, et al. Metabolic and immune integration in aging and age related disease aging. Albany NY; 2014. Jan;6(1):3-4. DOI: 10.18632\%2Faging.100626

4. Feng L, Ng TP, Larbi A, et al. Frailty in older person: multisystem risk factor and the Frailty Risk Index (FRI) in Duke University. Journal of the American Medical Directors Association; 2014. DOI: 10.1016/j.jamda.2014.03.008

5. Jacobs J.M, Cohen A, Ein-mor E, et al. Frailty, cognitive impairment and mortality among the oldest old. The Journal of Nutrition, Health and Aging; 2011.15(8):678682. Avalaible from: https://www.ncbi.nlm.nih.gov/pubmed/21968864.

6. Qingwei R, Zhuowei Yu, Zhijun B, et al. Cognitive Frailty, A Novel Target for Prevention of Elderly Dependency. Ageing Research Reviews; 2015.20:1-10. DOI: 10.1016/j.arr.2014.12.004

7. Robertson DA, Savva GM, Kenny RA. Frailty and Cognitive Impairment; A review of evidence and causal mechanism. ELSEVIER; 2013.12:840-850. DOI: 10.1016/j.arr.2013.06.004

8. Soysal P, Veronese N, Thompson T, et al. Relationship between depression and frailty in older adults: A systematic review and meta-analysis. ELSEVIER; 2017. DOI: 10.1016/j.arr.2017.03.005

9. Hutagalung RB, Aisha N. Analisis faktor-faktor yang mempengaruhi perilaku konsumen terhadap keputusan menggunakan dua ponsel (gsm dan cdma) pada mahsiswa Departemen Manajemen Fakultas Ekonomi USU. Jurnal Manajemen Bisnis; 2008.1(3):97-102. Avalaible from: http://repository.usu.ac.id/handle/123456789/11060

10. Kurlowicz L, Wallace M. Mini Mental Stage Examination (MMSE). The Hartford Institute for Geriatric Nursing; 2012. DOI: 10.3928/0098-913419990501-08

11. Greenberg, Sherry A. The Geriatric Depression Scale (GDS). Hartford Institute for Geriatric Nursing, NYU Collage of Nursing; 2012. Avalaible from: https://clas.uiowa.edu/sites/clas.uiowa.edu.socialwork/fil es/NursingHomeResource/documents/GDS.pdf

12. Anonymous. Proyeksi penduduk menurut kelompok umur dan jenis kelamin 2011-2020 (Online); 2017. Avalaible from: https://malangkota.bps.go.id.

13. Lang P.O, Michel J.P, Dina Z, et al. Frailty syndrome: A transititional state in a dynamic process. Gerontology; 2009.55:539-549. DOI: 10.1159/000211949

14. John St, Philip D, Tyas SL, et al. Depressive symtomps and frailty. International Journal of Geriatric Psychiatry; 2012.10:3866. DOI: $10.1002 /$ gps.3866

15. Mezuk B, Lohman, Edwards L, et al. Depression and frailty in later life: A synthetic review. International Journal of Geriatric Psychiatry; 2011. DOI: 10.1002/gps.2807

16. Kim Sun, Jun Li Park, Hwan Sik Hwang. Correlation between frailty and cognitive function in non-demented community dwelling older koreans. Korean J Fam Med; 2014.35(6):309-320. DOI: 10.4082/kjfm.2014.35.6.309

17. Leritz E.C, Ida Kellison et al. Cardiovascular disease risk factor and cognition in the elderly. PMC; 2011.5(5):407412. DOI: $10.1007 / \mathrm{s} 12170-011-0189-\mathrm{x}$

18. Fan CW, Aine M, Cogan L, et al. Frailty, depression, and anxiety in later life. International Psychogeriatrics; 2012.24(8):1265-1274.

DOI: $10.1017 / \mathrm{S} 1041610211002110$

19. Vaughan L, Akeesha L Corbin. Depression and frailty in later life: A systematic review. PMC; 2015.10:19741958. DOI: $10.2147 /$ CIA.S69632

20. Buigues C, Cauli Omar et al. The relationship between depression and frailty syndrome: A systematic review. Aging And Mental Healt; 2014.12:562-573. DOI: 10.1080/13607863.2014.967174 